https://helda.helsinki.fi

\title{
Knowledge Creating Inquiry In a Distributed \\ Project-Management Course
}

\section{Muukkonen, Hanni}

2010

Muukkonen , H , Lakkala , M , Kaistinen , J \& Nyman , G 2010 , ' Knowledge Creating Inquiry In a Distributed Project-Management Course ', Research and Practice in Technology Enhanced Learning. , vol. 5 , no. 2 , pp. 73-96 . https://doi.org/10.1142/S1793206810000827

http://hdl.handle.net/10138/28882

https://doi.org/10.1142/S1793206810000827

publishedVersion

Downloaded from Helda, University of Helsinki institutional repository.

This is an electronic reprint of the original article.

This reprint may differ from the original in pagination and typographic detail.

Please cite the original version. 
Research and Practice in Technology Enhanced Learning

Vol. 5, No. 2 (2010) 73-96

(c) World Scientific Publishing Company \&

Asia-Pacific Society for Computers in Education

DOI: $10.1142 / \mathrm{S} 1793206810000827$

\title{
KNOWLEDGE CREATING INQUIRY IN A DISTRIBUTED PROJECT-MANAGEMENT COURSE
}

\author{
HANNI MUUKKONEN*, MINNA LAKKALA ${ }^{\dagger}$, \\ JYRKI KAISTINEN ${ }^{\ddagger}$ and GÖTE NYMAN ${ }^{\S}$ \\ Institute of Behavioural Sciences \\ University of Helsinki, P.O. Box 9 \\ 00014 University of Helsinki, Finland \\ *hanni.muukkonen@helsinki.fi \\ ${ }^{\dagger}$ minna.lakkala@helsinki.fi \\ ${ }^{\ddagger}$ jyrki.kaistinen@helsinki.fi \\ §gote.nyman@helsinki.fi
}

\begin{abstract}
The investigation examined how to simulate practices of distributed, partially virtual teamwork in higher education. A course was designed to engage ten teams in producing solutions to complex problems, similar to that in knowledge work. The teams researched and prepared final reports and project presentations (shared objects) based on assignments from two customers. The course design provided templates and communication structures, but the teams needed to self-organize in order to carry out their own goals. Two analyses examined how the arranged project promoted practices of distributed, hybrid knowledge work and how the students coped with the knowledge creation challenge. Based on the team interviews half-way through the course, the students were confused and even distressed with the open-ended assignment. At the end of the course, their self-reflections revealed a change to more positive appraisals of the assignment. It was concluded that there were two types of practices involved, project work and inquiry, which might be best supported with different types of scaffolding, the first pragmatic or structural and the latter epistemic. This course presents an example of how workplace practices can be modeled for education, but also points to needs for scaffolding challenging team processes.
\end{abstract}

Keywords: Collaborative inquiry; distributed virtual project; knowledge creation.

\section{Knowledge Creating Inquiry in a Distributed Project Management Course}

In recent years, several researchers in education-related areas have argued that teachers, and educators generally, should pay proper attention to overcoming the mismatch between current knowledge work practices and the way students are being prepared in higher education to become competent knowledge workers

*Hanni Muukkonen's present affiliation: Department of Teacher Education, Faculty of Behavioural Sciences, P.O. Box 9, FIN-00014, University of Helsinki, Finland. 
(e.g., Bereiter, 2002; Bucciarelli, 2003; Hakkarainen, Palonen, Paavola \& Lehtinen, 2004; Stankovic, 2009). However, adopting the practices of workplaces in a straightforward manner does not appear to be the answer, because they may not provide relevant experiences from the pedagogical viewpoint. Stankovic (2009) proposed that higher education students' projects do not become realistic by taking on a model from a workplace, but by creating a model that takes on the key elements from the workplace and makes them realistic for the educational environment. This offered a valid approach and generated questions about how to simulate practices of distributed teamwork: Which are the key elements to be taken over and how does one assess their feasibility in educational settings? In this paper, the first analysis takes the view point of the students: how the students perceived their learning processes and experiences of distributed teamwork. Secondly, we took the perspective of the knowledge-creating-inquiry challenge put forth by the customers and the teachers: What did the teams produce and what kinds of inquiry practices did the teams adopt to cope with the concept development assignment.

In order to address these questions, we investigate a course on distributed project management. We present the theoretical background on knowledge creating inquiry, research on distributed teamwork (also the content of the course), as well as research on educational practices for simulating complex knowledge practices. In addition, we examine the role technology plays in mediating team interaction and collaboration practices.

\section{Knowledge Creating Inquiry}

We draw upon models describing knowledge creation that delineate collaboration as organized around long-term efforts for developing shared epistemic objects and practices (Bereiter, 2002; Engeström \& Blackler, 2005; Hakkarainen et al., 2004; Paavola \& Hakkarainen, 2005). The term epistemic object has been used to refer to an entity or effect that is for the most part unknown and taken under study (Knorr-Cetina, 1999; Miettinen, 2005; Rheinberger, 1997). Examples of such objects are theories, plans, protocol procedures, design drawings, prototypes, and collective practices. Epistemic objects are of interest because they portray the types of uncertainty and incompleteness present in evolving work practices, where multiple interpretations on knowledge and practices co-exist and are being created.

Knowledge creating inquiry, addressed in this paper, is defined as an educational practice that seeks to foster the above mentioned collaboration practices of working on shared epistemic objects. We examine a case from higher education, where project teams had their own knowledge creation assignments. The course design was intended to induce knowledge work practices aiming at producing solutions to ill-defined problems. Two customers were recruited by the teachers, and they provided the innovation challenges for the teams. The teachers supported the teamwork through a communication and project work structure - a distributed project model - but left the specific topics under the general course theme ill-defined and 
the working practices for the student teams to design. Another distinctive characteristic of the setting was that students from three universities participated in the course and worked together on the assignments; hence students had to adapt to collaboration with different domain backgrounds, technical, business, and psychology, as well as with the customers.

\section{Distributed Project Management}

In present-day organizations, the ability to work and manage collaboration in distributed teams and projects is becoming a key success factor. At least four dominant knowledge- work problems have been recognized. Firstly, organizations struggle with constant overload of knowledge, and teamwork is considered the best solution for remedying it. Secondly, business is international and globalized, which requires good practices for distributed teamwork via technological tools. Thirdly, all organizations are valued for their ability to generate innovations. Fourthly, extensive distributed subcontracting is becoming the way in which most industries operate.

Managing teamwork in workplaces entails having an overview of various patterns of interaction (Fiol \& O'Connor, 2005) as well as the team's documentation (Ewenstein \& Whyte, 2009). Members of co-located teams have opportunities for face-to-face interaction when creating and revising the shared knowledge objects. However, the present-day distributed teams are often "hybrid". A hybrid team refers to a blend of co-located and distant members; this introduces a heightened need for transparency in the communication of the coordination of activities. The distant members of such a team may experience being in the dark if good practices for communication and collaboration are not established (Fiore et al., 2003). Teams interacting purely virtually are strongly reliant on communication and collaboration technologies (Jarvenpaa \& Leidner, 1999; Lipnack \& Stamps, 1997; Powell, Piccoli \& Ives, 2004). In educational settings, such a hybrid set-up is equivalent to blended learning environment, where a team may meet during seminars or team sessions, but collaborates also virtually (e.g., Graham, 2006; Garrison \& Vaughan, 2008; So \& Brush, 2008).

Staples and Webster (2007) have reviewed studies on virtual teamwork practices and relate self-efficacy for teamwork to four central concepts useful in diagnosing virtual teamwork problems: the need to communicate well, willingness to share knowledge and time with others, efficient use of one's time, and support for the team spirit. Further, Bosch-Sijtsema, Ruohomäki, and Vartiainen (2009) have assessed knowledge work productivity in distributed teams and propose a model that integrates (1) time spent on tasks, (2) team structure and composition, (3) team processes, (4) alignment of workspaces, and (5) organizational context. In our study, we focused on the team processes because the course capitalized on organizing and managing teamwork and communication within teams and between teams (coordination team and other teams). In the work of Bosch-Sijtsema and colleagues (2009), team processes were framed as interpersonal, and the characteristics that 
were of interest were mutual trust, high autonomy, strong team identity, few personal conflicts, and high cohesion. Also, they distinguished planning processes (goal setting, clarity of roles and goals, and shared norms), and action processes. The latter included coordination of distributed teams, effective team communication, and high and motivated participation.

\section{Educational Practices for Simulating Complex Knowledge Work}

Carrying out customer projects in higher education is a long-standing practice, especially prominent in business, engineering, and design studies (e.g., Denton \& McDonagh, 2005; Marttiin, Nyman, Takatalo \& Lehto, 2004; SeitamaaHakkarainen, Lahti \& Hakkarainen, 2005). Having professional organizations involved is desirable for multiple reasons: it puts students in touch with the actual working practices and expertise in client organizations; it stimulates the exchange of knowledge in respect of recurring problems, methods, tools, and domain knowledge; and it supports transitions from education to work.

Prior findings have suggested that collaborative learning based on authentic problems can be successful when students are advanced in their studies and wish to prepare for the challenges of authentic practices (Carr-Chelman, Dyer \& Breman, 2000; see also McCune, 2009). Further, interdisciplinary or multi-professional education is argued to amplify relational, mediated, transformative and situated dimensions of learning and creativity (Latucca, 2002; Manathunga, Lant \& Mellick, 2006; Derry \& Fischer, 2005).

There is, however, a need for more clarity about what is vital in the design of courses intended to simulate complex practices such as distributed project management and inquiry. From the teacher, it requires a solid understanding of the practices under examination and an extensive contact network, which can offer authentic knowledge work challenges. Synchronizing team and customer contributions as well as supervising numerous concurrent projects are new demands on teachers' expertise (Lakkala, Kosonen, Bauters \& Rämö, 2008a).

At the same time, authentic practices are hardly definable by equitable standards although there are institutional needs to evaluate learning gains normatively. This leads to the questions about defining and measuring learning gains. Addressing this issue, Bucciarelli (2003) claimed that disjunction exists between the social practices of (engineering) design and the instrumental practices of educating engineers. He particularly criticized the latter for reducing knowledge to static, distributable entities, where problem-solving usually takes place in a linear, unambiguous, and de-contextualized process. Bucciarelli called for students to be evaluated "on the basis of the way they justify assumptions and estimates; on the way they explore a range of possible configurations" (p. 307) as well as application of the concepts and principles of the course.

Another problem is what constitutes an appropriate time-span for assessing the development of competencies for solving complex problems. Using only the 
few weeks reserved for one course in a semester appears debatable. Kapur (2008) has provided evidence for the hidden efficacy of failure: a collaboration ending up not producing the correct outcomes generated significant improvements later on, possibly because students had learned to conceptualize and analyze the problems while struggling without success in the first place. These findings speak for the use of complex problems, which may have been difficult at the time, since they were associated with the development of corresponding skills when examined in a longer timeframe.

Nance (2000) reported a case, similar to ours, of combining a term project with cross-course collaborative activities, where the older students acted as project leaders. The students agreed that taking part in a hands-on experience of teamwork was invaluable because it provided them with a better understanding of what it takes to operate successfully in a group and a taste of real world project management activities. Concurrently, this real-world like quality had its setbacks: the students expressed significant frustration over the frequent confusion, miscommunications, and mid-project adjustments. Nance reflected, "the requirement that students take personal responsibility for their own time management, work organization, and self-discipline, while forced to meet rigid weekly project deadlines, seemed to be an extremely foreign concept to many students" (p. 303).

These reflections point to the distinct features of a highly challenging situation for students: they need to manage and generate their own activities in teams, which may be especially difficult for those with little working experience. In Stankovic's study (2009), students experienced that accountability and time management are important, and that effective project communication and learning also depends on documentation that must be correct, meaningful, and up to date. Furthermore, undertaking a complex process of collaborative design is likely to be accompanied by the feelings of ambiguity and uncertainty amongst the participants (Dym et al., 2005). Studies of Nance (2000) as well as Muukkonen and Lakkala (2009) have reported that more mature and experienced students show more extensive capabilities or metaskills in dealing with the ill-defined nature of the process.

Finally, in such educational practices, an important question is the proper balance between the goal of authenticity and openness of the student assignment, and the level of support or structuring that should be provided so that the situation is not a total trial and error experience for the students. This issue is central in the notion of scaffolding (Wood, Bruner \& Ross, 1976; Lakkala, Muukkonen, Paavola \& Hakkarainen, 2008b).

\section{Research Objectives}

The first research objective was framed by the fact that the investigated course was intended to simulate practices of distributed virtual (hybrid) teamwork. As the outcomes of teams' productions could not be exactly predefined, it did not appear meaningful to try to measure any fixed, content-based learning gains. Instead, we 
wanted to find out how the students perceived their learning processes and the experienced challenges in teamwork in the beginning and at the end of the course. The following research questions were examined:

(1) What kinds of learning expectations and outcomes do the students describe?

(2) What kinds of challenges do the students expect and report in virtual and multi-professional teamwork?

The second research objective addressed the knowledge creation challenge: the customers' assignment, together with the course design, presented a demanding challenge for the teams to find solutions in a self-organized manner. Naturally, the perspective of the customers offered valid insight into the success of the project work. We studied the following questions:

(3) What do the teams produce?

(4) What kinds of practices do the teams adopt?

(5) How do the students deal with the open-ended assignment?

\section{Method}

\subsection{Setting: Design of the distributed project management course}

We studied an undergraduate course (an earlier course year described in Marttiin et al., 2004), in which the whole process was organized as a distributed project management process aiming at creating, in expert teams, innovative problem solutions for a customer. The four teachers involved had extensive experience in higher education, business processes, and consulting, as well as a close contact to business networks. The teachers emphasized that the engine of the entire process lies in the introduction of the customers' problem. In a best case scenario, the authenticity of the problem feeds into motivation, students' own interpretations, passion for solving the problem as a team, agency and ownership of generated solutions, and responsibility over carrying out the project.

The teachers had developed the design of the course over five successive years, changing aspects of the pedagogical design based on the involved clients and types of assignments and the feedback from previous courses. They used "activity processes" as the structure according to which an entire course can be organized and (re)run and provided a "distributed project model" for the students to describe the phases and objectives of the activities.

The design of the four activity processes of the course consisted of: I Customer activation, II Course build-up, III Activity management, and IV Outcomes (see Figure 1). Each process was based on sub-processes, management control, and a common communication infrastructure. The model was intended to offer the teams explicit and robust structural support for the work process but to leave intra-team communication and knowledge-related activities floating, thus requiring genuine commitment and self-organization. 


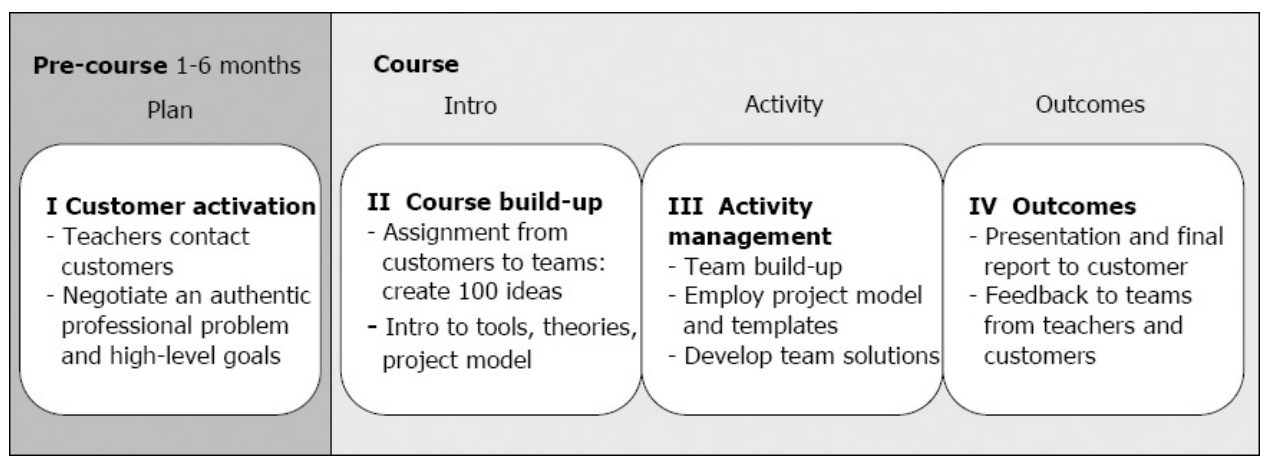

Figure 1. Design of the activity processes.

\subsubsection{Customer activation}

The customer activation preface was perceived as a central element for creating a successful set-up. The teachers used their knowledge and networks to find a match between customers that could benefit from a brainstorming type of concept development and a motivating assignment for the students. The teachers first developed some ideas among themselves and then discussed options with prospective customers. In this process, some higher level goals were formulated, which, however, left a great deal of freedom for the students. The teachers needed to consider whether the students had adequate competence for carrying out the assignment but, simultaneously, wanted to leave a risk margin for challenging the students to exceed their present knowledge and competencies.

\subsubsection{Course build-up}

The goal of the course was to get students acquainted with the theories, methods, and practices of organizing distributed work by participating themselves in a virtual teamwork process. A key characteristic of the course was that the distributed project model (see Figure 2) provided structure for the collaboration. The course design provided a setting where each team had a multi-curricular composition with a low amount of shared expertise and varying institutional practices of communication and collaboration. The theme was based on an assignment from two customers: determine the future possibilities and challenges of a broadcasting company in offering digital-TV services for people as workers, learners, citizens, and consumers or "Digi-human". The customers hoped to see 100 ideas not previously published nationally. The outcome of each team's work was a report and a presentation to the customer, which together described the team's solution; for example "Supplying services to the digital entertainment user" in Team 8, "MoveMove" attracting people into a more active lifestyle in Team 6, or "The future of music business — challenges and opportunities" in Team 5. Several teachers and 


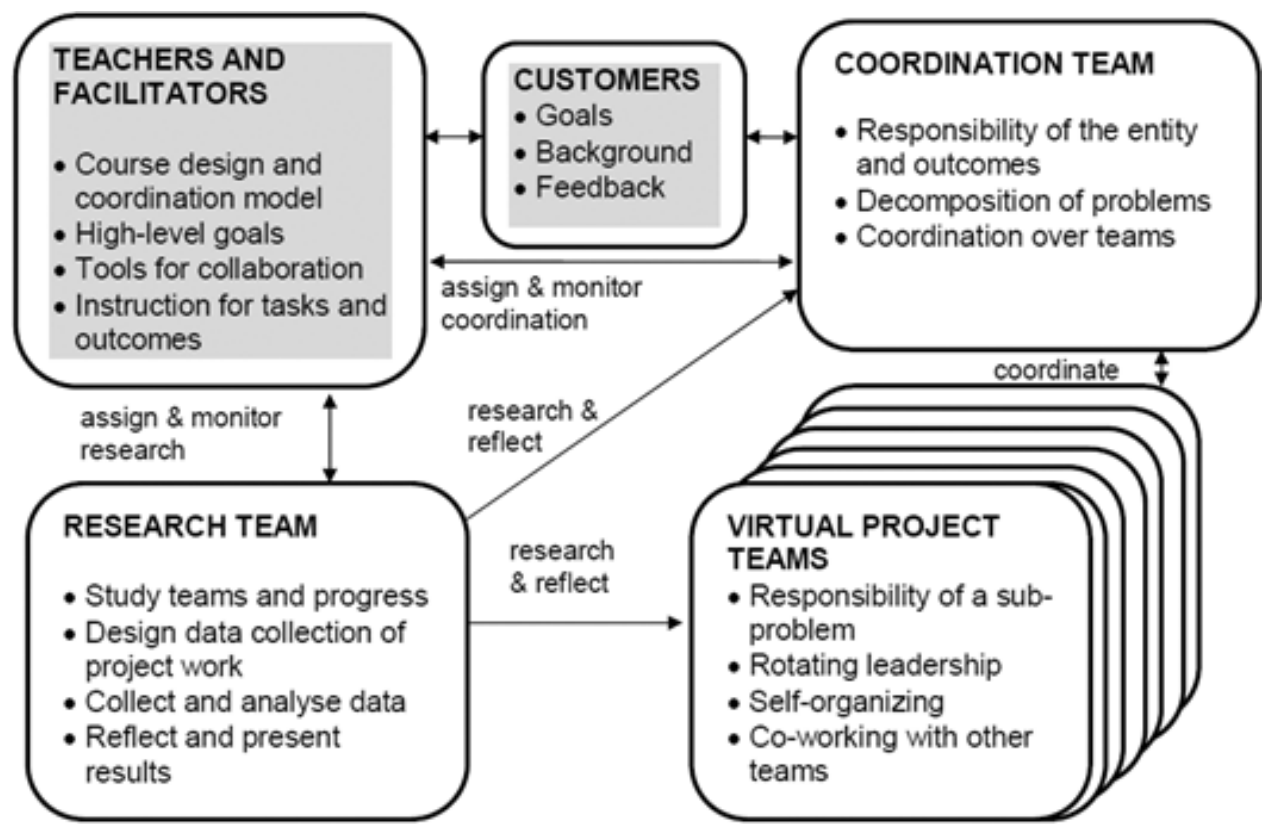

Figure 2. The distributed project model adapted from Marttiin et al., 2004. Boxes with white background indicate student teams.

tutors took part in the course as facilitators of students' work; metaphorically they were introduced as the board of directors, not directly involved in the execution of tasks.

\subsubsection{Activity management}

The Optima environment (described in Section 6.3) was assigned an important mediating role in structuring the collaboration practices in the project teams. The teachers presented the intended communication structure during a lecture, uploaded it in the environment with other resources (see Figure 3), and also designed the folder structure of the environment according to the activity phases for each team: definition, planning, execution, and delivery.

For each type of product, the students were furnished with templates, such as a team flyer, team diary, and a project plan. These were intended to provide scaffolding in the form of models and templates for engaging in various productions central in professional practices. Further, there were important constraints, such as the imperative of goal achievement, i.e., to produce a high-quality solution for the customers and to report and present it in front of the customer representatives, the self-organized team management and reporting practices, and the interaction with the customers for their requirements and feedback. A coordination team, composed of more advanced students, was given charge of the whole process of combining work 


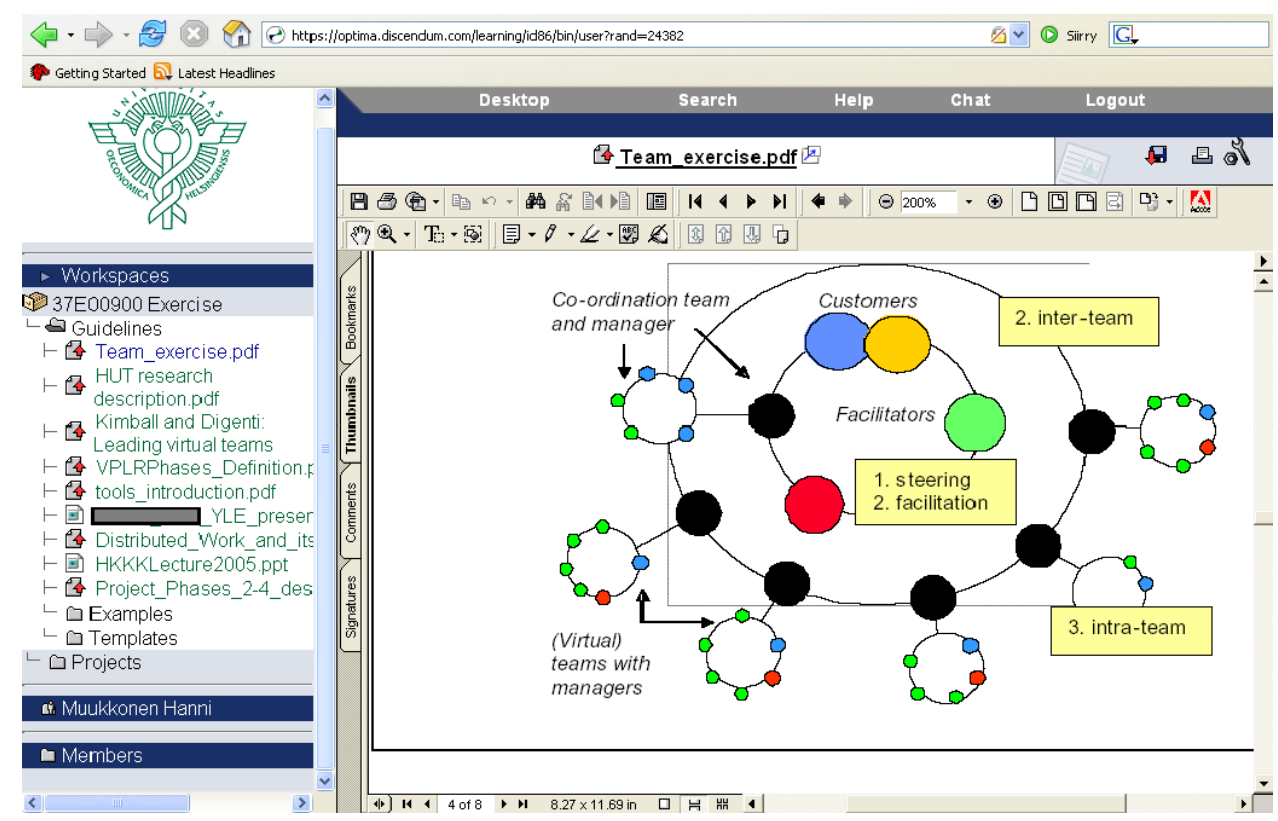

Figure 3. Screenshot from the Optima environment showing teachers' presentation about team communication structure.

in separate teams. The coordination team was responsible for communicating with the teachers and the customers; all communication from project teams towards these entities had to go through them. In all teams, the team management responsibility was rotating; in turn, each student was the manager in his or her team for 1-2 weeks. In addition to the coordination and project teams, another separate student group was a research team, which was responsible for studying and reflecting on the other groups' experiences.

\subsubsection{Outcomes}

The activity during the process was focused on producing the outcomes for the customers. In the first phase of the course, the coordination team collected the teams' "offers" for solving the customers' assignment and negotiated with the customers about carrying out the tasks. In the second phase, the coordination team passed on the sub-problems to teams, after which each team started focusing and planning how to conduct their study. In the third phase, based on the created solutions and usage of knowledge sources, each team constructed a half-an-hour presentation to the clients and a more extensive paper report. Throughout the phases, the coordination team supervised the teams, and the research team followed the process by questionnaires and interviews to study and report on team awareness and project management issues. 


\subsection{Participants}

The participants $(\mathrm{N}=47)$ were undergraduate students from three universities: 12 students from the Helsinki University of Technology, 21 students from the Helsinki School of Economics, and 14 students from the University of Helsinki, Department of Psychology. Six were foreign exchange students. From all participants, 18 students $(38 \%)$ were female. Knowledge of the university background was used to compose teams of $4-5$ students, with a multidisciplinary distribution of backgrounds in each team. Mean age and study year distributions as well as the average working experience in each team are presented in Table 1. Generally, the students were already far in their studies, on average in their fourth year of master's degree programs. The work experience varied from none to six years; members of teams 2,3 , and 6 , especially, had gained experience in professional practices. By contrast, teams 1, 4, and 7 were notably lower in terms of average age, year in studies, and working experience.

The course language was English, which presented an additional communication challenge for a few students. In addition to the four teachers, three tutors took part as facilitators of students' virtual collaboration. They mainly provided guidance with the collaboration tools.

\subsection{Collaboration tools}

The main collaboration tool used in the course was Discendum Optima (see http://www.discendum.com and the administrator website http://www.discendum. com/doc/learning/admininstructions.html), which is also used in work settings for project work. The Optima environment offers a virtual workspace where it is possible to add editable webpages accessible by the members of the course or project, create hierarchical folder structures, upload files, and use a discussion board. The teachers created two main folders, one for guidelines and materials, and another for the project teams (see Figure 4). The teachers and facilitators used the system for delivering general instructions and materials of the course and

Table 1. Mean age, year in studies, and working experience by team.

\begin{tabular}{lccc}
\hline Team & Mean Age & Mean Year in Studies & Mean Work Experience in Years \\
\hline 1 & 22.2 & 3rd & 0.5 \\
2 & 28.4 & 2 nd & 6 \\
3 & 26.5 & th & 6.3 \\
4 & 22.3 & 3rd & 0.8 \\
5 & 27.6 & 3rd & 3.1 \\
6 & 29 & 5 th & 5.3 \\
7 & 23 & 3rd & 0.4 \\
8 & 23.5 & 4 th & 4.5 \\
9 Coordination & 28.2 & 5 th & 3.1 \\
10 Research & 25 & 5 th & 0 \\
Total averages & 25.7 & 4 th & 3.8 \\
\hline
\end{tabular}




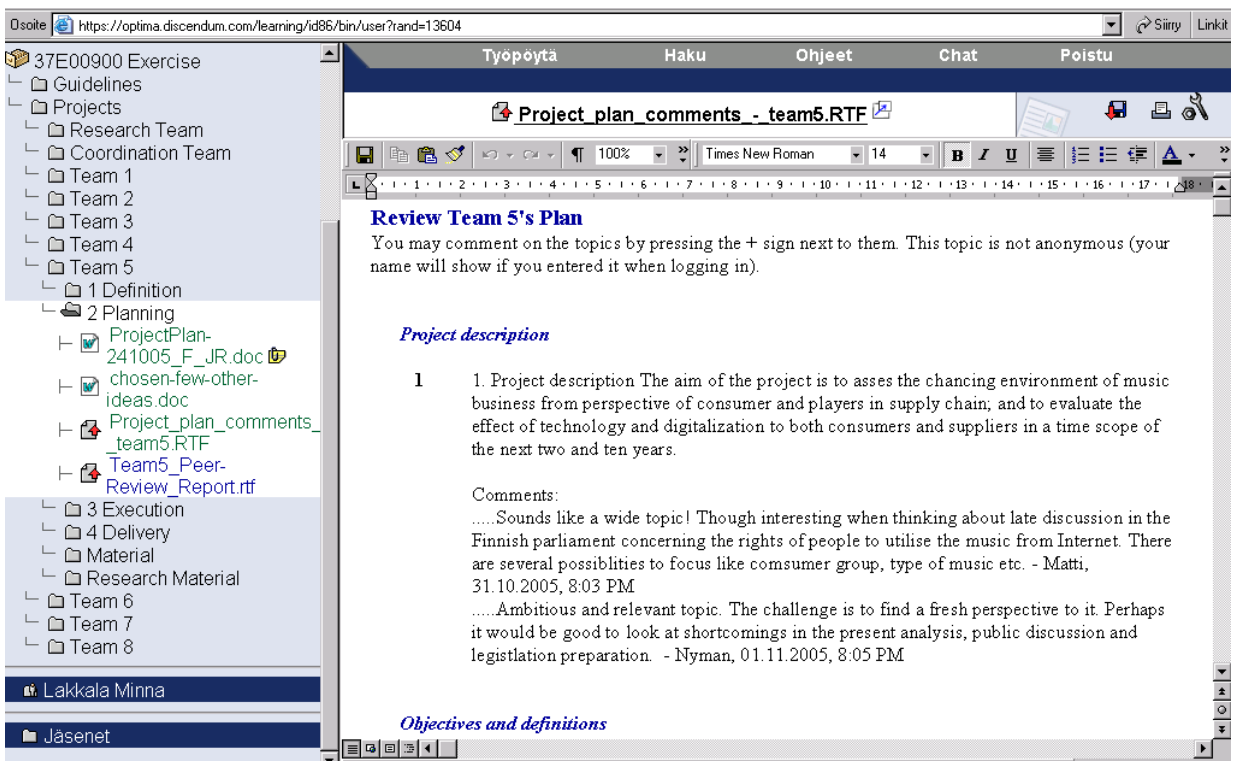

Figure 4. Screenshot from the Optima environment in left pane showing the folder structure with the selected file opened in the right pane.

for monitoring the teams' progress. The project teams used the system for storing documents, project manager diaries and status reports. They also used threaded discussions or comments in editable pages for intra- as well as inter-team communication (e.g., between coordination and project team) and communication with the teachers. Additionally, some teams experimented with the Facilitator.com tool (http://www.facilitate.com/) for brainstorming and commenting, but this data was not examined in the present study.

\subsection{Data-collection}

The data collected from the 12 weeks' course included database materials, students' pre and post self-reflective questionnaires, half-way course team interviews, team end-scores, and teacher interviews. In addition, we videotaped several lectures and feedback sessions where the customers participated, which have been used as reference material. An overview of the data-collection is presented in Figure 5. Interviews with the customer representatives were not arranged due to practical reasons; in hindsight, they would have yielded a highly important addition to the data set.

\subsubsection{Database materials}

All materials produced by the teachers and the student teams were collected from the Optima environment, including team productions, presentations, and final reports. 


\section{RESEARCH DATA}

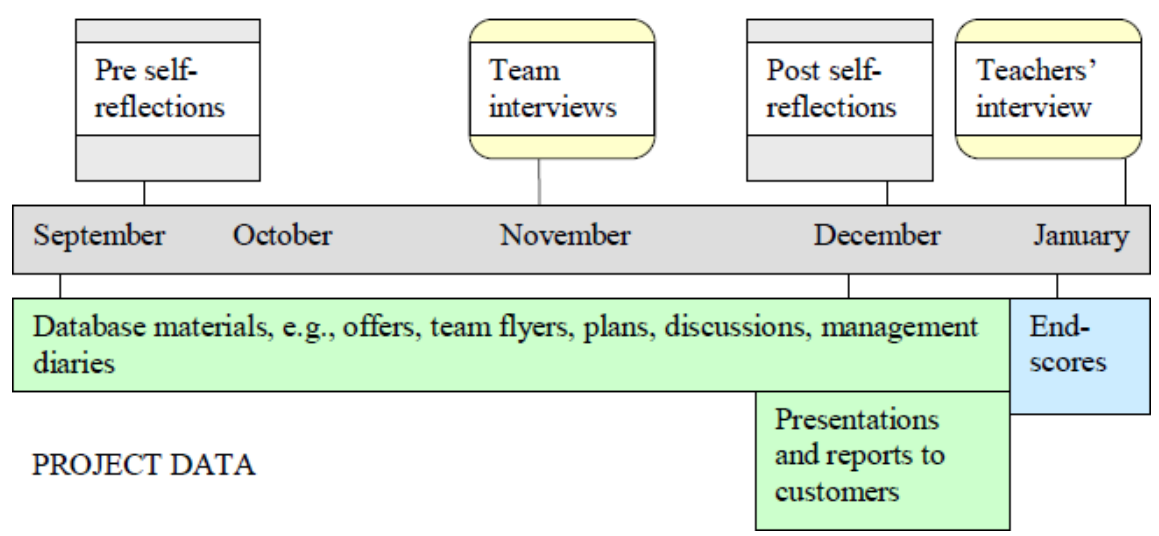

Figure 5. Overview of the data-collection.

\subsubsection{Self-reflective questionnaires}

By collecting pre and post self-reflections we wanted to contrast students' conceptual understanding and experiences from the beginning of the project work with those directly after the completion of team efforts. After the first two weeks of the course (pre-questionnaire) and after the last session of the course (post-questionnaire), the students were asked to answer to open-ended reflective questions. The questions and responses included in the analysis were on personal learning objectives and how they were met as well as their conceptualizations of the central content of the course; i.e., virtual teamwork and multi-professional teamwork. In all, 43 students out of 47 students responded to the pre-questionnaire and 44 to the post-questionnaire by e-mail.

\subsubsection{Team interviews}

Half-hour team interviews were conducted with teams 1-9. The interviews took place mid-way in the course, and 2-4 members were present in each team session. These structured interviews consisted of seven questions on team functioning (e.g., Are there aspects of the team's functioning that have been difficult or problematic?) and seven questions on the course content and problem solving process (e.g., How would you evaluate your team's productions and knowledge so far?).

\subsubsection{Presentations to customers}

Each team presented their work to the customers and the customers provided direct feedback on the solutions; these sessions were video recorded. 


\subsubsection{Team end-scores}

The teachers based the team evaluation on the following criteria; (a) Customer deliverables (70\%) including the innovativeness of ideas, completeness of deliverables (report, presentation), and framing of the research approach; (b) Project documentation (20\%) including team building, project planning, and follow-up deliverables; (c) Participation (10\%) to research activities and Facilitate.com usage (reviews, voluntary brainstorming).

\subsubsection{Teacher interview}

An interview with three teachers after the course completed the data collection. The teachers were asked to describe the construction of the course activity processes and to reflect on critical phases, roles of the participants, content, and the experiences gained from the course.

\subsection{Data-analysis}

\subsubsection{Qualitative content analysis of self-reflections}

Data analysis was focused on the students' self-reflective pre and post questionnaires. The responses to each question were read multiple times: the examination indicated that there were several ideas presented in each response; therefore they were segmented into ideas. Each idea would address only one category; the categories were mutually exclusive. A categorization was first data-grounded and then refined, based on the research questions. Several rounds of category development with the ATLAS.TI software were carried out to yield the present classification. The responses to the questions on virtual and multi-professional teamwork included several types of categories; definitions, challenges involved, and whether a change in the conceptions had changed. In the present paper we only address the challenges described. To analyze the inter-rater agreement of classification, an independent rater classified approximately $25 \%$ of self-reflection responses; the Kappa coefficient (Cohen's Kappa) for rater agreement was 0.78 for responses on learning, 0.84 for responses on challenges of virtual teamwork, and 0.84 for responses on challenges of multi-professional teamwork, which indicate high enough association between the two raters.

\subsubsection{Analysis of database materials}

The database materials were sorted into sub-types of assignments, e.g., project proposal or discussion note.

\subsubsection{Analysis of team and teacher interviews}

Team and teacher interviews were transcribed and thematically reviewed. In the team interviews, we paid particular attention to the account of team interaction 
patterns (how the teamwork had been initiated, how they met and how often), how each team described their practices of advancing the solutions for the customer, and their perceptions of the challenges of the assignment. In the examination of the teachers' interview, the role of the customer participation and design of the course activities, as perceived by the teachers, was central. Excerpts from both datasets are used as illustrative examples below.

\section{The Results}

\subsection{Learning about the practices of distributed teamwork}

In the first research question, we examined what kinds of learning expectations and outcomes the students described. The pre-questionnaire expectations (number of categorized segments $=66$ ) about learning were compared with the postquestionnaire responses $(n=96)$ about how the expectations about learning were met. The results show (Figure 6) that experience in project work and management was most often mentioned, but in the post-questionnaires, taking initiative and creating new knowledge as well as issues of participation and trust in the teamwork were emerging.

The second research question addressed what kinds of challenges the students expected (number of categorized segments $=118)$ and reported $(n=94)$ in virtual and multi-professional teamwork. The results (Figure 7) indicate that some challenges of virtual teamwork were perceived as relatively more central in the beginning phase: commitment and participation, ICT skills, personal qualities, negotiation of practices and rules, and time management. Other challenges, namely appropriate communication skills and means, leadership, planning and organizing, and trust were more often raised after the course.

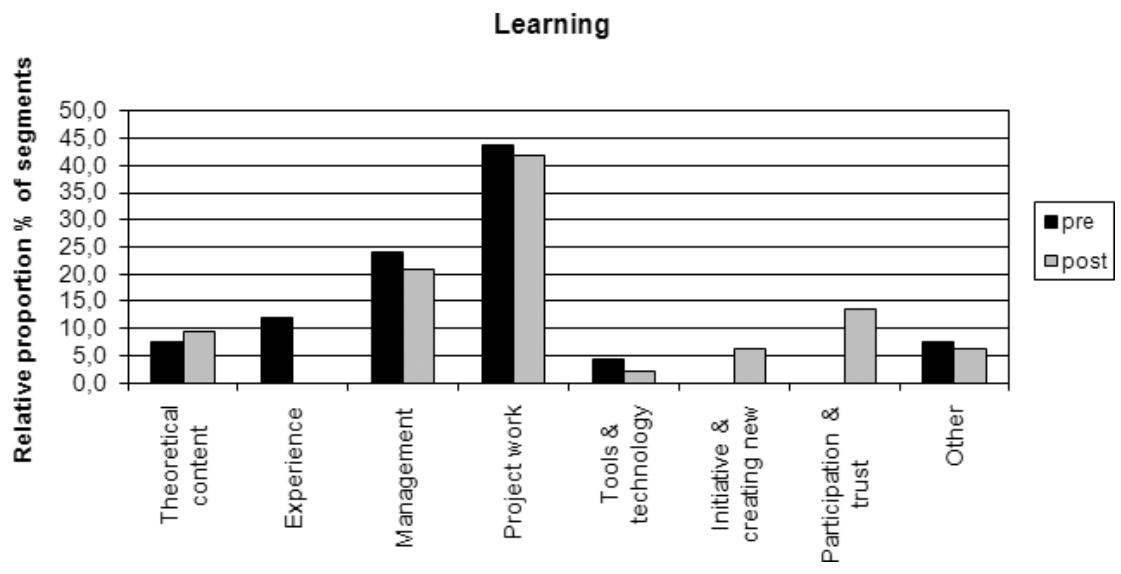

Figure 6. Learning expectations "What do you want to learn during the course?" and outcomes "What have you learnt during the course?" in pre and post self-reflections. 


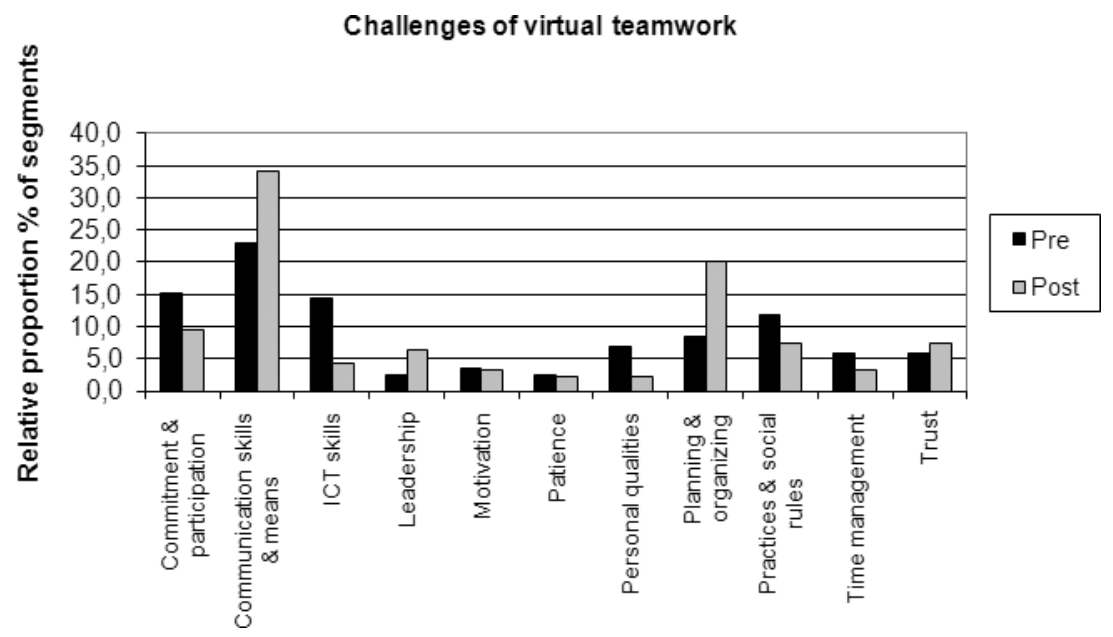

Figure 7. Challenges of virtual work in pre and post self-reflections.

There was a change in the direction of emphasizing the interpersonal and mediated aspects of collaboration; from personal qualities and time management to appropriate communication skills and means as well as planning and organizing teamwork. Monitoring individual forms of participation lost importance, whereas collaboration and collective organization around the shared object gained importance.

The challenges of multi-professional teamwork (see Figure 8) were described in the beginning $(n=75)$ as relating largely to finding a common language and understanding, being able to communicate effectively, and establishing common working practices. In post-course responses $(n=51)$, the experience of teamwork

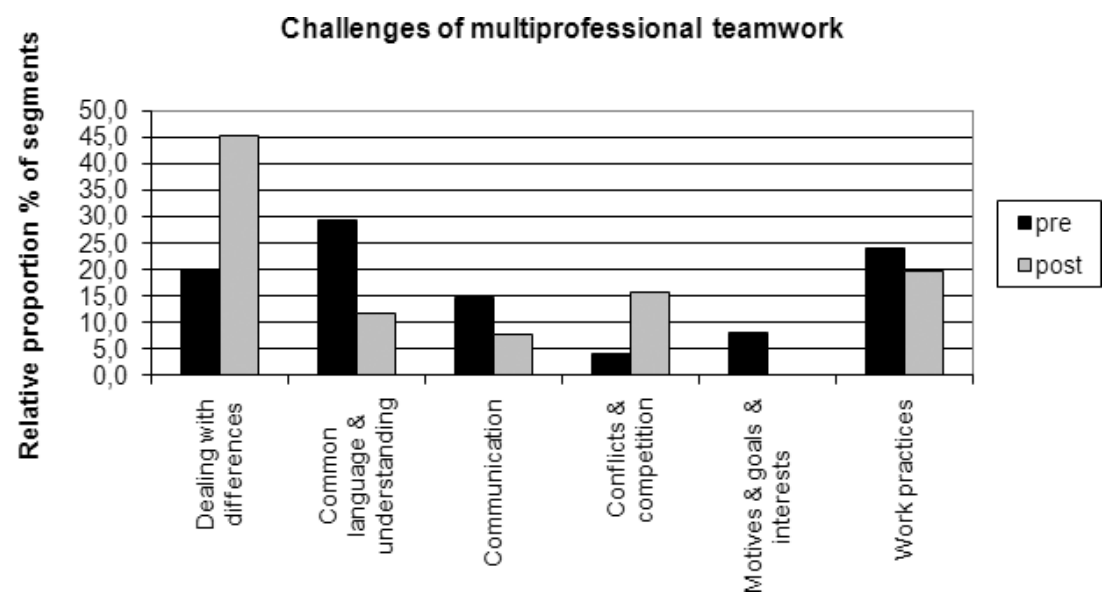

Figure 8. Challenges of multi-professional teamwork in pre and post self-reflections. 
with students from multiple professional backgrounds heightened the need to handle differences and competition. Creating common working practices also remained central.

\subsection{Devising team practices for facing the knowledge creation challenge}

The second main objective of the study was to examine the knowledge creation practices emerging in student teams. We started by analysing what the teams produced (research question 3). The Optima environment was used; participants operated with files, and the discussion forum notes were used more to exchange managerial information. As shown in Table 2, there was a large variation in the number of documents produced by teams. The team flyers, presentations, reports, and other materials, such as background materials, status reports, and diaries, were often versioned. Based on the number of versions, Teams 1, 5, 6, and 7 appear to have been especially focused on revising their productions. Teams 1 and 7 stand out as having a large amount of discussion forum notes; they had organized their virtual communication mainly through the Optima environment, while others mainly used email. Team 8 showed very low activity in posting documents or discussion notes. The coordination team (Team 9) and research team (Team 10) had different types of responsibilities in the project; they were not expected to produce all the types of documents developed in teams 1-8.

The team end-score revealed that the research team was awarded a full 60 points for their extensive research efforts, and the other teams received all above satisfactory level scores. Judged from the team end-scores, the teams with younger participants $(1,4$, and 7) did as well as more experienced student teams. Therefore, the expectation that older students would do better was not confirmed in this comparison based on the average age and study experiences.

Table 2. Objects developed by students in the Optima environment and team end-scores.

\begin{tabular}{|c|c|c|c|c|c|c|c|c|c|c|}
\hline & \multicolumn{10}{|c|}{ Team } \\
\hline & 1 & 2 & 3 & 4 & 5 & 6 & 7 & 8 & $9^{\mathrm{a}}$ & $10^{\mathrm{b}}$ \\
\hline Documents in Optima & 61 & 23 & 16 & 35 & 59 & 55 & 64 & 14 & 9 & 23 \\
\hline Team flyer & 10 & 2 & 1 & 6 & 6 & 1 & 8 & 1 & 0 & 0 \\
\hline Team rules & 1 & 2 & 1 & 0 & 2 & 2 & 0 & 2 & 3 & 0 \\
\hline Project proposal & 6 & 4 & 2 & 6 & 1 & 2 & 0 & 0 & 0 & 0 \\
\hline Project plan & 5 & 4 & 2 & 3 & 3 & 3 & 16 & 2 & 0 & 0 \\
\hline Presentation & 1 & 1 & 1 & 2 & 2 & 7 & 4 & 3 & 1 & 1 \\
\hline Report versions & 4 & 3 & 2 & 5 & 5 & 15 & 10 & 3 & 0 & 0 \\
\hline Other materials & 34 & 7 & 7 & 13 & 40 & 25 & 26 & 3 & 5 & 22 \\
\hline Discussion forum notes & 198 & 90 & 14 & 71 & 14 & 41 & 180 & 1 & 62 & 25 \\
\hline Team end-score $(\max 60)$ & 54 & 53 & 50 & 50 & 55 & 46 & 55 & 44 & 52 & 60 \\
\hline
\end{tabular}


For answering the fourth research question, we analyzed the database materials and the mid-course team interviews to find out what kinds of practices the teams had adopted. Overall, differences in the working practices between teams were apparent: some were more inclined to meet face-to-face, while others collaborated mainly virtually. Common, however, was that the more they reported having met face-toface (and thus learned to know each other and negotiate their practices), the more fluent they judged their collaboration in the team interviews. This result echoes research from virtual teamwork: Face-to-face meetings during a project launch have been found to facilitate socialization and trust among team members, and periodic face-to-face meetings improved coordination of activities (e.g., Maznevski \& Chudoba, 2001; Powell et al., 2004). The Optima environment used in the course was criticized by all teams because they experienced difficulties with the cluttering of information from many teams, usability, finding the right areas, searching for and printing materials. Several teams reported, however, that they had actively used it for storing their files, coordinating activities, and communicating with the Coordination team.

Based on the analysis of the transcripts of the team interviews, we have selected three teams, 8,6 , and 5 , to present examples. These are two project teams with the lowest grades ( 8 and 6 ) and one team (5) with the highest grade. As all teams carried out the course work satisfactorily, we were interested in the qualitative differences that could be identified in the processes of the lowest and highest achieving teams, and further, how the students described their knowledge creating inquiry.

For Team 8, the start-up of collaboration appears to have been difficult; they had managed only one face-to-face meeting while trying to communicate through email. Altogether, this team communicated very thinly in Optima, and they generally just submitted one version of each of their documents, without doing editing and versioning, at least not in Optima. They pointed to the problem of asynchrony in communication. They had settled for dividing the tasks between them, without having a clear apprehension of what the goals of their group work should be. One student said: our biggest difficulty has been to make all our expectations about this course to match together after the start, how we consider it and how we continue working together (Team 8).

The course objective of providing the participating customers a real outcome had been taken seriously by this group, although they were very apparently still questioning, at the time of the interview, whether their final results would meet the demands: when we go with the final report to the client, that what is the value they should give to the report, after all, we haven't conducted real research with value, its more like ideas during schoolwork just because we had to write something about it and make it look good, that the base of research is quite shaky (Team 8).

In their final report, the team wrote: "The most important lessons are not so much related to the results of our study, but the process of performing a study like this. [...] Getting to know each other and each others['] way of working took much more time than we expected. Also decision-making process was slower due to the 
asynchrony nature of communication. These were both things we had heard and read about but we had not been able to take advantage of this knowledge in our initial preparations. Now, at the end of the project we probably all have a slightly more realistic idea of the challenges of virtual teamwork."

At the end of the course, this team received the lowest team score. However, their work met all the requirements, and was valued for constructing a good framework of the approach, showing many ideas, and a fitting analysis and consideration of the customer's potential. Following their presentation, a customer commented that the presentation was at the core of the questions discussed internally and that these "ideas support, very well, the thinking that already exists" in the organization.

Team 6 had also only once met face-to-face by the time of midway interviews. They had started to use MSN messenger-meetings as their preferred collaboration environment, and stored documents in Optima. They considered the distribution of tasks between members to be efficient. Towards the end, this team was the most active in versioning their report: 15 versions were uploaded to the database. In the interview, when asked which factors were difficult in the team's functioning, one team member explained: "chaos, but I'm not completely sure if it was purposeful or not, that we did not get any clear structure, which probably in real life would be given" (Team 6). Another member continued, "I'm somewhat expecting some kind of grand finale at the end, then everything falls to places and clears up... and we do some fine outcomes in teamwork. But on this moment, it has been unclear and little by little we have by ourselves managed a little more" (Team 6). These excerpts are descriptive of the expectations they held about getting a clear scope of the task from the teachers - which was not fulfilled - and about their positive expectation for the teamwork. Their reflections on the challenge of taking hold of an ambiguous process are typical; without the predefined content and practices, the need to self-organize becomes apparent.

Regarding the customers' expectations, they thought that they had not exactly met the demands of producing many ideas, but had focused on advancing a smaller set. They received an above satisfactory end-score and were commended by teachers for clear and good scenarios, a holistic approach to the problem, and expressive and fluent documentation suitable for requirements elicitation. The customers also liked the concepts, although still raw, and perceived them as ideas the kind of that could actually be incorporated in the future.

Team 5 had a strong emphasis on collaboration: they had met weekly face-toface, carried out questionnaire studies and interviews to get material for their report, and assessed that everyone had participated well in teamwork. They were equally puzzled by the ambiguity of instructions in the beginning, but had clearly taken a self-determined and adaptive approach in organizing the objectives of teamwork. "It's true, but this is such a creative process, it's difficult to say which direction it is taking, we have a meeting next week, we have not decided what we should do by then, but it could be that something new or a new point has come up by then which changes everything, really difficult to say" (Team 5). 
The following is an exchange between two students in Team 5, on the question, "how have you found out new knowledge to answer your team's task?".

Nina: We have been distributing some tasks; someone has dug into this subject and someone else into another, searched for articles via the net and read some magazines.

Mikko: Generally, we have gone ahead based on where each of us has their interest in, searched through that route knowledge for the entire team.

Nina: But it has not been very precise, the process of collecting knowledge and searching, its more like we have had too much knowledge.

Mikko: Yes, that we could mention, that we have talked a lot and that has cultivated new points, which someone has taken up and searched more info about it, based on what was said in the discussions.

As shown in the transcript, this team struggled with the pervasive knowledge work problem of having too much information. Yet, they tackled it effectively by refocusing, searching for more precise information, and thus cultivating their ideas. This was one of the few teams that conducted in-depth searches into their problemarea.

This team had made deliberate efforts to make plans for carrying out their work and sharing responsibilities. This team carried out a web-based survey with consumers, conducted interviews with record company bosses, and generally, uploaded an abundance of materials and documents in the virtual environment. At the end, they received, from the teachers, a high grade for their team products and were especially commended for the excellent service/application concepts, the realistic potential in the ideas, and a stunning amount of empirical work. After the team's presentation, the customers engaged in a great deal of discussion, some of it also critical, about the concepts and ideas presented.

Overall, the customers were very keen to know when the more extensive report versions would be available to use as materials in internal discussions. In the presentation session, they assessed that, from the ca.100 ideas presented by teams, about 15 could be implemented directly in the organizations.

\subsection{Dealing with confusion}

Following the last research question, we examined how the students dealt with the demands of the open-ended assignment. As expressed in the team interviews halfway through the course, the students were confused and even distressed with the open-ended assignment and with managing team activities. Half-way the course, students would typically say that "Actually, although in the beginning nobody knew what we were supposed to do, now that we have just started to do something, we have managed" (Team 7).

In the post self-reflections, we observed a change in the interpretations of the value of such open-ended assignment. We analyzed the responses to the questions 
'What kind of experience was it to take part in the course? What was good, what was bad, why?' From the evaluated experiences, $62 \%$ were positive, $15 \%$ were negative, and $23 \%$ were mixed ratings. On the positive side, a typical response was that "I was left with a good feeling since I could finally see the results of the work and note that the challenge could be pulled through" (Team 1). The complexity of the ill-defined task and managing the hybrid teamwork was often reflected on in terms of learning what not to do the next time: "At least I learned many things that shouldn't be done when working virtually or when having a virtual project" (Team 2). Many of the negative or mixed ratings pointed to a lack of guidance and unclarity of the learning goals, which the students attributed to the course design.

Overall, the students mentioned challenges: overcoming a sense of frustration and confusion; trusting a project that they could not understand fully in the beginning; managing a culture-diversified team; and devising practices for co-authoring and advancing their reports. In some cases, the teams acknowledged the importance of intra-team communication in defining own goals, as displayed in the following excerpt from post self-reflections: "Our communication was very efficient, as we managed to redefine our team's goals and schedules many times along the way to correspond to changing situations, at the same time keeping in mind the official goals" (Team 10).

\section{Discussion and Conclusion}

The paper is motivated by questions, What are the key elements of knowledge work to be transferred from the workplace to educational settings? And how does one implement them and assess their feasibility in an educational setting? The design of the course points to some of our tentative answers, that is, teamwork based on customers' complex and challenging assignments; our analyses specify others.

The first research objective was to examine whether the course could simulate the professional practices of distributed virtual teamwork on epistemic objects. The results revealed that the concrete experience expanded students' conceptions about various aspects of managing collective activities: communication skills and means, planning and organizing activities, and the importance of participation and trust. Similar aspects have been identified in literature characterizing distributed teamwork relating particularly to team processes (reviewed by Bosch-Sijtsema et al., 2009), which suggests that a high degree of authenticity of teamwork practices and challenges — was achieved by the course design. Other aspects mentioned by Bosch-Sijtsema and colleagues, such as time on task, team structure, workspaces, and organizational context, were addressed to a lesser degree, presumably because they were predefined by the course design itself (relating to team structure and time on task) or they were not applicable to the tasks at hand in an educational context (relating to the particulars of an organizational context).

It appears that the choice to introduce particular limited aspects of the distributed teamwork was fruitful. Central importance in the course design was given 
to the simulation of team processes, which itself was highly demanding for students. Several constraints may also be set by the educational setting, for instance, the intense, predefined timeframe was coupled with the teachers making the selection of team members and setting the phases for creation of project plans, reports and presentations. The course did not aim to engage students in the communities of practice (Lave \& Wenger, 1991; Wenger, 1998) of the customer organizations, which would have required a more reciprocal relationship with the customer. Although the customers were only peripherally involved in the course, they nevertheless had an important function in the course design: As intended by the teachers, their presence and assignment appears to have provided a solid motivation for the project teams, establishing relevance for the participating students (Kember, Ho \& Hong, 2008). Simultaneously, the customers valued the outcomes of the concept development process.

The second research objective was to examine the knowledge creation challenge: the customers' assignment, together with the course design, presented a strong challenge for the teams to find solutions in a self-organized manner. We witnessed in the pre-questionnaire and the mid-course team interviews that students were quite confused and anxious about how they should proceed. In the post-questionnaires, the students regarded the course as instructive on project management and, importantly, the teams produced solutions that were considered better than satisfactory and gained the full attention of the customers. It can be hypothesized that finding common understanding about the form of the presentation and report (the shared objects) led to some decrease in confusion. Another explanation is that the course work was constructed so that there were, at regular intervals, small deadlines for project deliverables (e.g., project plans and team flyers), and the teams could feel to progress by accomplishing these. Nonetheless, how the change from confusion to activation took place is a question for future examination, as our data-collection means did not capture it. As a data set, the self-reflections provided us with robust insights into students' expectations and experiences. However, a possibility to follow some teams' face-to-face interaction could have offered a vital point of reference with the self-reflections.

As an implication for educational practice, it is suggested that if students are given highly complex and challenging tasks, one should not be afraid nor avoid the confusion and insecurity in the beginning steps. Yet it is critical that the entire process be completed to get a feeling of success from the challenges. Leaving such a margin for uncertainty, especially in the lack of direct guidance regarding choices made by a team is not typical of education in the present type of setting. However, it is very characteristic of knowledge work, and therefore important to introduce as an element of knowledge creating inquiry, although extreme uncertainty is not desirable. Further, flexible educational technology could provide more varied types of mediation for a team's collaboration, including pragmatic, social, epistemic, and reflective types of activities (Paavola \& Hakkarainen, 2009; Rabardel \& Bourmaud, 2003). 
A comparison of how the teachers described the course objective and how the students approached it generated a discrepancy worthy of note. The teachers addressed the objective as distributed virtual project work, which was the content of the course and which they supported through the project model, templates, explicit phases, and deadlines. It appears, however, that for the students, the primary objective was to meet the knowledge creation challenge of the customers. We suggest that these represent two distinct types of practices, project work and inquiry, which are best supported with different types of scaffolding, the first pragmatic or structural and the latter epistemic. The pragmatic aspects of collective practices are highlighted by structures and phases of team activities and management of teamwork processes and products. The epistemic aspects, on the other hand, are highlighted by scaffolding for advancement in understanding, material resources, and ways to collaboratively design and version shared objects. At the same time, research on distributed, virtual teamwork also appears to emphasize the structural aspects of collaboration (cf., a review on virtual team research literature by Powell et al., 2004 or management of virtual teams by Hertel, Geiser \& Konradt, 2005), raising the question whether epistemic aspects of knowledge practices should be more explicitly addressed in professional teamwork. In future, the course design could be enriched by explicitly modeling and scaffolding the epistemological advancement and concrete strategies of inquiry.

Efforts to bridge educational and professional contexts in the way exemplified by the course design requires one to rethink educational practices, resourcing, and evaluation, but also creates very compelling knowledge creation opportunities for all participants.

\section{Acknowledgments}

We thank Pentti Marttiin, Matti Vartiainen, the participating assistants and students, and the customer representatives for their cordial collaboration. We also wish to extend our thanks to Hal White, the Editor, and the anonymous reviewers for suggestions for improvements on earlier versions of the manuscript.

\section{References}

Bereiter, C. (2002). Education and Mind in the Knowledge Age. Hillsdale: Erlbaum.

Bosch-Sijtsema, P. M., Ruohomäki, V., \& Vartiainen, M. (2009). Knowledge work productivity in distributed teams. Journal of Knowledge Management, 13, 533-546.

Bucciarelli, L. L. (2003). Designing and learning: A disjunction in contexts. Design Studies, 24, 295-311.

Carr-Chellman, A., Dyer, D., \& Breman, J. (2000). Burrowing through the network wires: Does distance detract from collaborative authentic learning? Journal of Distance Education, 15(1), 39-62.

Denton, H. \& McDonagh, D. (2005). An exercise in symbiosis: Undergraduate designers and a company product development team working together. The Design Journal, $8,41-51$. 
Derry, S. J. \& Fischer, G. (2005, April). Toward a Model and Theory for Transdisciplinary Graduate Education. Paper presented at the meeting of the American Educational Research Association, Montreal, Canada. Retrieved August 25, 2010, from: http://13d.cs.colorado.edu/ gerhard/papers/transdisciplinary-sharon.pdf

Dym, C. L., Agogino, A. M., Eris, O., Frey, D. D., \& Leifer, L. J. (2005). Engineering design thinking, teaching, and learning. Journal of Engineering Education, 94(1), $103-120$.

Engeström, Y. \& Blackler, F. (2005). On the life of the object. Organization, 12, 307-330.

Ewenstein, B. \& Whyte, J. (2009). Knowledge practices in design: The role of visual representations as 'epistemic objects'. Organization Studies, 30, 7-30.

Fiol, C. M. \& O'Connor, E. J. (2005). Identification in face-to-face, hybrid, and pure virtual teams: Untangling the contradictions. Organization Science, 16, 19-32.

Fiore, S. M., Salas, E., Cuevas, H. M., \& Bowers, C. A. (2003). Distributed coordination space: Toward a theory of distributed team process and performance. Theoretical Issues in Ergonomics Science, 4, 340-364.

Garrison, D. R. \& Vaughan, N. D. (2008). Blended Learning in Higher Education. San Francisco: Jossey-Bass.

Graham, C. R. (2006). Blended learning systems: Definition, current trends, and future directions. In C. J. Bonk, \& C. R. Graham, C. R. (Eds.) Handbook of Blended Learning: Global Perspectives, Local Designs (pp. 3-21). San Francisco, CA: Pfeiffer Publishing.

Hakkarainen, K., Palonen, T., Paavola, S., \& Lehtinen, E. (2004). Communities of networked Expertise: Professional and Educational Perspectives. Advances in Learning and Instruction Series. Amsterdam: Elsevier.

Hertel, G., Geiser, S., \& Kondadt, U. (2005). Managing virtual temas: A review of current empirical research. Human Resources Management Review, 15, 69-95.

Jarvenpaa, S. L. \& Leidner, D. E. (1999). Communication and trust in global virtual teams. Organization Science, 10, 791-815.

Kapur, M. (2008). Productive failure. Cognition and Instruction, 26, 379-424.

Kember, D., Ho, A., \& Hong, C. (2008). The importance of establishing relevance in motivating student learning. Active Learning in Higher Education, 9, 249-263.

Knorr-Cetina, K. (1999). Epistemic cultures: How the Sciences Make Knowledge. Cambridge, MA: Harvard University Press.

Lakkala, S., Kosonen, K., Bauters, M., \& Rämö, E. (2008a). Cross-fertilization of collaborative design practices between an educational institution and workplaces. Poster presented at the 4th EARLI SIG 14 Learning and Professional Development Conference, 27.-28.8.2008. University of Jyväskylä, Jyväskylä, Finland.

Lakkala, M., Muukkonen, H., Paavola, S., \& Hakkarainen, K. (2008b). Designing pedagogical infrastructures in university courses for technology-enhanced collaborative inquiry. Research and Practice in Technology Enhanced Learning, 3, 33-64.

Latucca, L. R. (2002). Learning interdisciplinarity. The Journal of Higher Education, 73, 711-739.

Lave, J. \& Wenger, E. (1991). Situated learning: Legitimate Peripheral Participation. Cambridge, MA: Cambridge University Press.

Lipnack, J. \& Stamps, J. (1997). Virtual Teams. New York: Wiley.

Manathunga, C., Lant, P., \& Mellick, G. (2006). Imagining an interdisciplinary doctoral pedagogy. Teaching in Higher Education, 11, 365-379.

Marttiin, P., Nyman, G., Takatalo, J., \& Lehto, J. A. (2004). Learning virtual project work. In J. Cordeiro \& J. Filipe (Eds.), Computer Supported Activity Coordination. Proceedings CSAC 2004 (pp. 91-102). Portugal: Insticc Press. 
Maznevski, M. L. \& Chudoba, K. M. (2001). Bridging space over time: Global virtual team dynamics and effectiveness. Organization Science, 11, 473-492.

McCune, V. (2009). Final year biosciences students' willingness to engage: Teachinglearning environments, authentic learning experiences and identities. Studies in Higher Education, 34(3), 347-361.

Miettinen, R. (2005). Object of activity and individual motivation. Mind, Culture, and Activity, 12, 52-69.

Muukkonen, H. \& Lakkala, M. (2009). Exploring metaskills of knowledge-creating inquiry in higher education. International Journal of Computer Supported Collaborative Learning, 4, 187-211.

Nance, W. D. (2000). Improving information systems students' teamwork and project management capabilities: Experiences from an innovative classroom. Information Technology and Management, 1, 293-306.

Paavola, S. \& Hakkarainen, K. (2005). The knowledge creation metaphor - An emergent epistemological approach to learning. Science \&f Education, 14, 535-557.

Paavola, S. \& Hakkarainen, K. (2009). From meaning making to joint construction of knowledge practices and artefacts - A trialogical approach to CSCL. In C. O'Malley, D. Suthers, P. Reimann, \& A. Dimitracopoulou (Eds.), Computer supported collaborative learning Practices: Proceedings of the 9th international conference of Computer Supported Collaborative Learning, Volume 1 (pp. 83-92). International Society of the Learning Sciences [ISBN: 978-1-4092-8598-4].

Powell, A., Piccoli, G., \& Ives, B. (2004). Virtual teams: A review of current literature and directions for future research. The DATA BASE for Advances in Information Systems, 35, 6-36.

Rabardel, P. \& Bourmaud, G. (2003). From computer to instrument system: A developmental perspective. Interacting with Computers, 15, 665-691.

Rheinberger, H. J. (1997). Toward a History of Epistemic Things: Synthesizing Proteins in the Test Tube. Stanford, CA: Stanford University Press.

Seitamaa-Hakkarainen, P., Lahti, H., \& Hakkarainen, K. (2005). Three design experiments for computer-supported collaborative design. Art, Design $\&$ Communication in Higher Education, 4(2), 101-119.

So, H.-J. \& Brush, T. A. (2008). Student perceptions of collaborative learning, social presence and satisfaction in a blended learning environment: Relationships and critical factors. Computers \& Education, 51, 318-336.

Stankovic, N. (2009). Single development project. The Journal of Systems and Software, 82, 576-582.

Staples, D. S. \& Webster, J. (2007). Exploring traditional and virtual team members' "best practices": A social cognitive theory perspective. Small Group Research, 38(1), 60-97.

Wenger, W. (1998). Communities of Practice: Learning, Meaning, and Identity. Cambridge, MA: Cambridge University Press.

Wood, D., Bruner, J. S., \& Ross, G. (1976). The role of tutoring in problem solving. Journal of Child Psychology and Psychiatry, 17, 89-100. 